\title{
A high mean-HbA1c value 3-15 months after diagnosis of type 1 diabetes in childhood is related to metabolic control, macroalbuminuria, and retinopathy in early adulthood - a pilot study using two nation-wide population based quality registries
}

Ulf Samuelsson, Isabelle Steineck and Soffia Gubbjornsdottir

Linköping University Post Print

\section{Tweet}

N.B.: When citing this work, cite the original article.

Original Publication:

Ulf Samuelsson, Isabelle Steineck and Soffia Gubbjornsdottir, A high mean-HbA1c value 315 months after diagnosis of type 1 diabetes in childhood is related to metabolic control, macroalbuminuria, and retinopathy in early adulthood - a pilot study using two nation-wide population based quality registries, 2014, Pediatric Diabetes, (15), 3, 229-235.

http://dx.doi.org/10.1111/pedi.12085

Copyright: Wiley http://eu.wiley.com/WileyCDA/

Postprint available at: Linköping University Electronic Press http://urn.kb.se/resolve?urn=urn:nbn:se:liu:diva-107850 
Running Title: Metabolic control in adults and children

Corresponding author: Ulf Samuelsson

Department of Clinical and Experimental Medicine, Division of Pediatrics and Diabetes research centre, Linköping University Hospital, Linköping, S-581 85 Sweden.

Phone: +46101030000

Fax: +4613148265

Mail: ulf.samuelsson@lio.se 
A high mean-HbA1c value 3-15 months after diagnosis of Type 1 diabetes in childhood is related to metabolic control, macroalbuminuria and retinopathy in early adulthood - a pilot study using two nation-wide population based quality registries.

Ulf Samuelsson, ass prof*, Isabelle Steineck, MD** and Soffia Gubbjornsdottir, ass prof ${ }^{\#}$

* Department of Clinical and Experimental Medicine, Division of Pediatrics and Diabetes. Research Center, Linköping University Hospital, Linköping, Sweden

** Emergency room, Herning Hospital, Herning, Denmark

\#Dept of Medicine, Sahlgrenska Hospital, University of Gothenburg, Gothenburg, Sweden

Word count: 5,165. 4,789 (running title, title side and abstract excluded) 


\begin{abstract}
Background: Intensive treatment of patients with type 1 diabetes delays the onset of long-term complications.
\end{abstract}

Objectives: Based on information from two nation-wide quality registers, we investigated to which extent HbA1c values 3-15 months after diagnosis in childhood are related to metabolic control, albuminuria and retinopathy in early adulthood.

Methods: In Sweden, physicians register all children and adolescents with type 1 diabetes mellitus in the Swedish Pediatric Quality Registry. After 18 years of age, people with diabetes are followed by the Swedish National Diabetes Register. We identified 1,543 children and adolescents with a mean age of 13.9 years at diagnosis and a mean duration of type 1 diabetes mellitus of 7.1 years.

Results: Children and adolescents with poor metabolic control (mean $\mathrm{HbA} 1 \mathrm{c} \geq 70 \mathrm{mmol} / \mathrm{mol}$ $(8.6 \%))$ adjacent to diagnosis had a significantly higher mean HbA1c value years later as adults than did patients with a good metabolic control $(<50 \mathrm{mmol} / \mathrm{mol}(6.7 \%)(\mathrm{p}<0.001))$. The patients in the high group were also less physically active and smoked more as adults. The proportion of females was higher in the poor metabolic group. Patients with a high mean HbA1c 3-15months after diagnosis had significantly more often macroalbuminuria and retinopathy in early adulthood.

Conclusions: Metabolic control adjacent to the diagnosis of type 1 diabetes in childhood or adolescence can predict metabolic control in early adulthood. It is therefore very important that pediatric diabetes teams identify key factors for successful early metabolic control. Actively using quality registries may be one such factor.

Key words: Hbalc quality register, albuminuria, retinopathy 


\section{Introduction}

Previous studies have shown that intensive therapy of subjects with type 1 diabetes mellitus delays the onset of long-term complications and slows the progression of complications $(1,2$, 3). The Diabetes Control and Complication Trial (DCCT) was the first to show this, using either multiple daily insulin injections or an insulin pump to improve metabolic control imeasured by $\operatorname{HbA} 1 \mathrm{c}(1)$.

Several studies have reported that microvascular complications in kidneys and eyes are usually first diagnosed after the child reaches puberty. This can easily lead to the assumption that prepubertal periods have a minor impact on the development of late complications (4). However, recent studies have shown that children with diabetes are vulnerable to microvascular complications (5). The level of HbA1c during the years immediately after diagnosis is found to be related to later metabolic control $(6,7,8,12)$. This may suggest metabolic memory (11). It is reasonable to assume that metabolic control in a person with T1D depends on both psychosocial and biological factors. However, we know rather little about the relative importance of these factors. Examples of psychological factors include the parents' educational background, logistical competence, self-discipline, and the wish to support the children's needs $(7,8)$. The child's personality, status within its circle of friends, and psychological health can also be expected to influence metabolic controls $(7,8)$. We can add to this the family's resources, relative to social network and finances. Another important factor is how the policy and approaches of healthcare teams affect glycemic control in children and adolescents (9). Biological factors include to what extent some beta cells continue to produce insulin.

Although the importance of metabolic control at the time of diagnosis on later metabolic control has been studied, we only have studies with rather short follow-up during childhood, and its effect on metabolic control and complications in early adulthood is not known. Studies carried out during a shorter follow-up indicate an association $(5,6)$. For example Shalitin and Phillip studied 173 children who had been diagnosed with type 1 diabetes before they had reached the age of 6.5 years (5). In the 53 children in whom the value of HbAlc at the time of initial diagnosis was less than $7.5 \%$, the mean value of HbA1c six years after diagnosis was $6.8 \%$. For children who had a mean value equal to, or greater than, $7.5 \%$, the corresponding value six years after diagnosis was HbA1c $8.4 \%$. The difference between the two groups is statistically significant. A limitation in the study by Shalitin and Phillips is that they included 
only children who had been diagnosed before reaching 6.5 years of age, and thereby excluded 218 children of the total of 1150 patients who were diagnosed at the Schneider Children's Medical Center of Israel (5). Of these 218, 175 who met the study criteria were excluded from the study, a rather large number. Given these limitations, additional studies of this relationship are needed. Gender differences have also been found and girls in the 6-12-year age group presented with higher HbA1c levels than did boys and girls of other age groups $(6,13)$. Moreover, during clinical course, poorer metabolic control has been found in girls than in boys, especially during adolescence $(14,15,16)$ In addition, a higher incidence of DKA, dyslipidemia and height problems occurred more frequently in female patients (14).

Sweden offers excellent opportunities for following individuals with type 1 diabetes mellitus over a long period of time. Every Swedish resident has a unique personal identity number. This makes it possible to follow individuals and to link information from various populationbased registers. We have used this platform to study the extent to which $\mathrm{HbA1c}$ concentration 3-15 months after diagnosis, before and after puberty, is related to the HbA1c concentration at 18-29 years of age.

\section{Patients and Methods}

\section{The Swedish pediatric diabetes quality registry, SWEDIABKIDS}

Outpatient attendance data from all Swedish pediatric diabetes centers are registered in SWEDIABKIDS (SWE), established in 2000. SWE was stepwise and randomly introduced during the years since more and more clinics chose to participate and in the year 2007 all 43 pediatric clinics were included in the registry. All diabetes teams have from the start included all their patients. In Sweden, pediatric clinics treat all children and adolescents aged 0-18-19 years (in some cases up to 20 years of age) with diabetes from defined geographic areas. Thus the registry includes since 2007 data on almost all (around 99\%) children and adolescents with diabetes in Sweden. In 2010, the registry included data from more than 235,000 outpatient visits.

Initially, from 2000 to 2007, data were registered locally by doctors and/or nurses in a specially designed program for childhood diabetes. The registry has been web-based since 2008 and is available to all pediatric diabetes centers in Sweden. According to the Swedish guidelines, children with diabetes visit the diabetes center at least 4 times/year. At these visits 
HbA1c and other clinical parameters such as insulin dose, weight, length and blood pressure are measured and reported by trained nurses or physicians online (http://www.ndr.nu/ndr2).

\section{The Swedish National Diabetes Register, NDR}

The NDR was introduced in 1996 to collect data on clinical characteristics and various risk factors in diabetic patients over 18 years of age at outpatient clinics of departments of medicine and primary health care centers nationwide. The aims of the NDR are to monitor diabetes care and encourage registration of all diabetics at least once a year. Reporting to the NDR is not obligatory, but all clinics and health care centers are encouraged to participate. The patients are reported over the Internet (http://www.ndr.nu) or by transferal from medical records databases. As with SWE more and more clinics have during the years randomly chose to participate in NDR and in 2012 were somewhat more than $90 \%$ of the adult patients with type 1 diabetes included (National Diabetes Register, Year Report 2012).

Both SWEDIABKIDS and the NDR are financially supported by the Association of Local Authorities and Regions, SALAR, which represents the governmental, professional and employer-related interests of Sweden's municipalities county councils and regions (URL: http://english.skl.se/ [accessed august 2011]). Both registries have the status of a national quality registry, and the patients are informed about the register before agreeing to be included. It is worth mentioning that none of the registries collect data, and are not allowed to, on ethnicity, socioeconomic status, educational level and so on.

All laboratory methods used in Sweden are standardized through EQUALIS (External Quality Assurance in Laboratory Medicine in Sweden). The data on HbA1c obtained from SWEDIABKIDS and NDR were derived from capillary blood samples taken in connection with the visit to the diabetes center or the outpatient clinic. All available HbA1c values between 3 - 15 months after diagnosis were used (i.e. 4 - 5 values) and averaged. The mean value is calculated as follows: first the mean for each patient and from that the mean $\mathrm{HbA} 1 \mathrm{c}$ value for SWE and NDR, respectively. In NDR all available values were used for the mean HbA1c value. The IFCC reference method has been adopted in Sweden, and HbA1c values will be presented both as NGSP/DCCT (\%) and as IFCC (mmol/mol)(10). For example, 58 $\mathrm{mmol} / \mathrm{mol}$ (IFFC) corresponds to $7.5 \%$ (NGSP/DCCT), $10 \mathrm{mmol} / \mathrm{mol}$ is about $0.9 \%$. Microalbuminuria was defined as urine albumin excretion 20-200 $\mu \mathrm{g} / \mathrm{min}$ and macroalbuminuria as urine albumin excretion $>200 \mu \mathrm{g} / \mathrm{min}$ in two out of three consecutive tests. Physical activity is divided in 5 levels: never (level 1), less than one time/week (level 2), 
one-two times/week (level 3), three-five times/week (level 4) and daily (level 5). Physical activity is defined as activity more the 30 minutes.

\section{Study populations}

During the years up to 2010, 6289 patients with Type 1 diabetes have moved from SWE, as they have reached adulthood, to the NDR. Of these was 4854 (77.2\%) identified in NDR and of these 4854 patients, we have information from 1543 patients' HbA1c values during months 3-15 after diagnosis (Table 1). The 3311 patients with no HbA1c values registered months 3 - 15 after diagnosis had somewhat fewer males (53.7 \%), were slightly younger $(12.4 \pm$ 2.9 years) but had about the same mean-HbA1c in SWE and NDR $(62.4 \pm 14$ and $69 \pm 15$ $\mathrm{mmol} / \mathrm{mol}$ ) as the 1543 children with $\mathrm{HbA1c}$ values registered during these months.

As SWE was randomly introduced and included all pediatric clinics first from 2007 there are 7 years where many patients were treated for and diagnosed with diabetes but not included. As adults they could be included in NDR. There are 3520 patients with Type 1 diabetes registered in NDR who were diagnosed during childhood according to age and year of diagnosis.

Some of the patients have been included in SWE for a long time and for only a short period in the NDR, whereas other patients have the opposite pattern. As a rule, the patients visit the pediatric clinic as a child four times each year, and as an adult make two visits each year to a medicine clinic or a primary health care center. Most of the patients have been within the NDR for 2-4 years. The patients had a mean number of 19.5 visits within SWE and 4 visits within the NDR. The mean age in SWE is $13.9 \pm 2.5$ years and the mean age in the NDR is 21 \pm 2.3 years, range $18-29$ years of age; 159 patients are 18 years and four are 29 years. The mean duration of follow-up is $7.1 \pm 2.5$ years (range $1-12$ years).

\section{Statistical analysis}

SPSS $18^{\circledR}$ (SPSS inc., Chicago, IL, USA) was used for the analyses. Student's t-test and oneway analysis of variance (Anova) were used. When there were indications of skewed 
distribution, Mann-Whitney U-test or Kruskall Wallis test was used. Groups were compared by crosstabs, and chi-square was used for proportions. To test the relationship between $\mathrm{HbA1c}$ adjacent to diagnosis and HbA1c during early adulthood we used Spearman correlation. A multivariate logistic regression model was used to investigate the risk for complications. A multivariate linear regression with mean HbA1c in NDR as dependent and mean HbA1c months 3 - 15 after diagnosis as independent was also used in order to adjust for potential confounders. A p value $<0.05$, two-sided was regarded as statistically significant. The results are expressed as mean $\pm \mathrm{SD}$. 


\section{Results}

Table 1 shows mean HbA1c at 3-15 months after diagnosis in relation to age at diagnosis. Very few of the patients in this cohort are diagnosed before 10 years of age and none before 5 years of age. This is logical as SWEDIABKIDS started in 2000 and included all pediatric patients with diabetes from 2007 and later, and patients diagnosed very early in life have therefore not reach the age of 18 years in 2010. Another explanation is that when the clinics choose to participate in the registry they included all their actual patients but included very seldom the patients $\mathrm{Hba1c}$ values and other parameters from the beginning. As expected, most of the patients were males (59.6\%). Children diagnosed at $5-9$ years of age had a higher mean HbA1c 3-15 months after diagnosis than older children; this difference between the age groups was significant, $\mathrm{p}<0.001$ (Table 1). Girls had in general a slightly higher mean HbA1c than boys.

Patients with poor metabolic control during month 3-15 after diagnosis, defined as HbA1c $\geq$ $70 \mathrm{mmol} / \mathrm{mol}$ (8.6\%), had a significantly higher HbA1c years later in the NDR, both as mean and as the last HbA1c compared with patients with good metabolic control $(\leq 50 \mathrm{mmol} / \mathrm{mol}$ $(6.7 \%))(\mathrm{p}<0.001)($ Table 2$)$. They were also younger at diagnosis and had longer disease duration, but about the same BMI and blood pressure in the NDR as the patients with good metabolic control. The proportion of girls was higher in the high HbA1c group than in the low group. The patients in the high group had also lower physical activity and smoked more often as adults (Table 2). A multivariate linear regression model also show this relation between mean-HbA1c months 3-15 after diagnosis and mean Hba1c in NDR, also after adjusting for potential confounders (Table 3 ).

As seen from Table 2, both albuminuria and retinopathy were significantly more common in the high $\mathrm{HbA1c}$ group compared with the group with good metabolic control and in the middle group (51-69 mmol/mol $(6.8-8.5 \%)$ ). Consequently, patients with macroalbuminuria in NDR had significantly higher HbA1c 3-15 months after diagnosis than patients without (65 $\pm 17,5 \mathrm{mmol} / \mathrm{mol}(8.6 \pm 1.6 \%)$ vs. $53 \pm 13.6 \mathrm{mmol} / \mathrm{mol}(7.0 \pm 1.2 \%), \mathrm{p}<0.001)$. This was also seen for patients with retinopathy $(56.9 \pm 14.1 \mathrm{mmol} / \mathrm{mol}(7.4 \pm 1.3 \%)$ vs. $52.3 \pm 13.5$ $\mathrm{mmol} / \mathrm{mol}(6.9 \pm 1.2 \%), \mathrm{p}<0.01)$ but not for those with microalbuminuria $(55.2 \pm 15.8$ $\mathrm{mmol} / \mathrm{mol}(7.2 \pm 1.4 \%)$ vs. $52.9 \pm 13.5 \mathrm{mmol} / \mathrm{mol}(7.0 \pm 1.2 \%), \mathrm{p}=0.16)$. Furthermore, logistic regression showed that patients in the high HbA1c group during month $3-15$ after 
diagnosis had an OR of 13.3 to develop macroalbuminuria compared to patients with good metabolic control $(\mathrm{p}<0.01)$ (Table 4). Corresponding figures for microalbuminuria and retinopathy were $1.9(\mathrm{p}<0.1)$ and $2.3(\mathrm{p}<0.01)$. When adjusting for gender, duration, age at diagnosis, physical activity and smoking the figures were about the same (Table 4).

The correlation between mean-HbA1c during months 3-15 after diagnosis and mean-HbA1c in early adulthood is also shown in Figure 1. A rather high proportion of the children (44\%) in the low HbA1c group had a low mean Hbalc value as adults $(\leq 57 \mathrm{mmol} / \mathrm{mol}(7.4 \%))$. The opposite pattern was also found; a very low proportion of the children (7\%) with high HbA1c in the beginning had low mean HbA1c as adults. In line with that, the children in the low HbA1c group had a significantly lower mean-HbA1c during their time in SWEDIABKIDS compared to both the children in the high group $(\mathrm{p}<0.001)$ and in the middle group $(<0.001)$ (Table 2). The mean-value difference is also significant between the middle and the high group $(\mathrm{p}<001)($ Table 2$)$.

We defined boys $\geq 14$ and girls $\geq 12$ years of age at diagnosis as being in puberty. Children diagnosed during or after puberty had lower $\mathrm{HbA} 1 \mathrm{c}$ after diagnosis than children diagnosed before puberty $(52 \pm 14 \mathrm{mmol} / \mathrm{mol}(6.9 \pm 1.3 \%)$ vs. $57 \pm 12 \mathrm{mmol} / \mathrm{mol}(7.4 \pm 1.2 \%)$, $\mathrm{p}<0.01)$. They have also had lower HbA1c during their time as children $(59 \pm 14 \mathrm{mmol} / \mathrm{mol}$ $(7.5 \pm 1.2 \%)$ vs. $65 \pm 10 \mathrm{mmol} / \mathrm{mol}(8.1 \pm 1.0 \%), \mathrm{p}<0.01)$ and as adults so far in the NDR $(66 \pm 15 \mathrm{mmol} / \mathrm{mol}(8.2 \pm 1.5 \%)$ vs. $69 \pm 10 \mathrm{mmol} / \mathrm{mol}(8.5 \pm 1.0 \%), \mathrm{p}<0.05)$. No significant differences were seen regarding BMI, and blood pressure and physical activity between these two groups. 


\section{Discussion}

In this population-based study with information from two databases in Sweden,

SWEDIABKIDS and the NDR we found that metabolic control adjacent to the diagnosis of type 1 diabetes mellitus in a child, measured by the level of HbA1c 3-15 months after diagnosis, correlates to metabolic control and complications in early adulthood.

We divided the patients in three groups by HbA1c values 3-15 months after diagnosis. The group with the best metabolic control during this time had also the best control as adults. In line with this, the group with early poor metabolic control had also poor metabolic control later on. In a study from the USA, Viswanathan and co-workers followed 120 children who had been diagnosed at a mean age of 7.6 years (6). They found a statistically significant correlation between $\mathrm{HbA} 1 \mathrm{c}$ at the time of initial diagnosis and $\mathrm{HbA} 1 \mathrm{c}$ three years later, independent of the type of insulin regime the patients had been following. A limitation of the study by Viswanathan and coworkers and the earlier mentioned study by Shalitin and Phillip (5) was the short follow up time and perhaps also the small numbers. The present populationbased study with longer follow-up and broader age interval at diagnosis confirms these results. Our results are also in line with a very recent population based study from Denmark (17), where they used a registry similar to SWEDIABKIDS. Moreover, this relationship is true up to early adulthood. As already described we also found that HbA1c levels were higher in children diagnosed before estimated puberty than after $(5,13)$. The present study also found that they continued to have higher levels as adults.

Poor control 3-15 months after diagnosis is not only correlated to poor metabolic control in early adulthood but also increases the risk of microvascular complications in early adulthood. We found that $5.7 \%$ with good metabolic control had microalbuminuria and $0.5 \%$ had macroalbuminuria compared with $8.2 \%$ and $5.6 \%$, respectively, in the poor metabolic group. The regression model showed no significant relation between the poor metabolic control and microalbumiuria but a rather high OR with the more severe form of albuminuria as well as retinopathy. From the Diabetes Control and Complication Trial, as well as other studies, we know that intensive therapy resulting in good metabolic control delays the onset of nephropathy, retinopathy and neuropathy $(1,2,12,18)$. Although this is not a randomized trial we found in this nationwide population based study focusing on children and early adulthood the same clinically important results. Since the middle mean-HbA1c group months $3-15$ 
after diagnosis did not develop albuminuria more than the low group it may indicate that albuminuria need rather high HbA1c values over time to occur.

We may well ask why the metabolic control values reported during the first year after the diagnosis of diabetes mellitus are correlated with control values in early adulthood. Several previous studies have shown that the family's total resources-economic, time commitment, and knowledge - explain why some children meet the demands for metabolic control better than others $(19,20)$. These studies indicate that children who manage to maintain strict control of blood-sugar values come from families who have more resources at their disposal than families whose children less successfully maintain satisfactory blood-sugar levels.

Unfortunately, such data is not yet included in the registries but SWE plan to include data of this type in the near future. Another mediating factor may be that if the diabetes team sets a high goal at diagnosis for the family's commitment to following recommendations for metabolic control, the family may continue that commitment at a high level (9). It may be more difficult to get the child to follow a program of tight metabolic control later on if he or she was unable to manage good metabolic control at the time of diagnosis. Other relevant factors may be more biological than social. We have not investigated gender differences in this study, but the proportion of females was highest in the high HbA1c group. This might imply that the metabolic control in the general diabetes population is poorer in females than males during the clinical course. Further studies are needed.

This observed association between metabolic control 3-15 months after diagnosis in childhood and metabolic control in adulthood underlines the importance of understanding the mechanism involved. Already in Sweden today, despite a better or comparable glycemic control than in other populations $(15,21,22)$, we see large differences in HbA1c between pediatric clinics. Earlier research using SWEDIABKIDS $(9,15)$ and on-going projects in the registry shows that the clinics with low annual mean-HbA1c values have well-functioning teams and aims at low HbA1c values already from start and gives clear messages to their patients. These clinics have not more severe episodes of hypoglycemia and/or ketoacidosis in their patients than the clinics with higher mean values, quite the opposite. Working with, and research on, registry data will allow us in the future to identify key factors for successful early metabolic control. In the near future SWEDIABKIDS is also going to include patient reported outcome measures (PROM) and it is therefore even more important for the pediatric diabetes teams to explore these relationships by actively using the quality registry. This will undoubtedly be very cost-effective. 


\section{Acknowledgments}

The Swedish board of Health and Welfare, the Swedish Association of Local Authorities and Regions. We thank the diabetes centers who have contributed to the study by registering data on the children, adolescents and adults with type 1 diabetes attending their diabetes center. We also thank Professor J Cederholm for valuable statistical advice.

\section{Conflict of interest}

No conflicts of interest to disclose 


\begin{tabular}{|c|c|c|c|c|c|c|}
\hline & \multicolumn{2}{|c|}{ Total } & \multicolumn{2}{c|}{ Male } & \multicolumn{2}{c|}{ Female } \\
\hline & Number & HbA1c (SD) & Number & HbA1c (SD) & Number & HbA1c (SD) \\
\hline 5-9 years & $89(5.8 \%)$ & $58.7 \pm 12$ & $51(5.5 \%)$ & $58.8 \pm 10$ & $38(6.1 \%)$ & $58.7 \pm 14$ \\
& & $(7.5 \pm 1.1)$ & & $(7.5 \pm 0.9)$ & & $(7.5 \pm 1.3)$ \\
\hline 10-14 years & $769(49.8)$ & $55.3 \pm 13$ & $431(46.8)$ & $54.8 \pm 12$ & $338(54.3)$ & $55.9 \pm 13$ \\
& & $(7.2 \pm 1.2)$ & & $(7.2 \pm 1.1)$ & & $(7.3 \pm 1.2)$ \\
\hline 15-19 years & $685(44.4)$ & $50.5 \pm 14$ & $438(47.6)$ & $50.3 \pm 14$ & $247(39.6)$ & $50.9 \pm 14$ \\
& & $(6.8 \pm 1.3)$ & & $(6.7 \pm 1.3)$ & & $(6.8 \pm 1.3)$ \\
\hline Total & 1543 & $53.4 \pm 14$ & 920 & $52.9 \pm 14$ & 623 & $54.1 \pm 14$ \\
& & $(7.04 \pm 1.3)$ & & $(7.0 \pm 1.2)$ & & $(7.1 \pm 1.3)$ \\
\hline
\end{tabular}

Table 1. Mean HbA1c months 3-15 in relation to age at diagnosis. The mean difference between the age groups is significant $(\mathrm{p}<0.001)$ in the whole group as well as in males and females. Figures with parenthesis are NGSP/DCCT-values. 


\begin{tabular}{|c|c|c|c|c|}
\hline & $\begin{array}{c}\text { All patients } \\
\mathrm{n}=1543\end{array}$ & $\begin{array}{c}\leq 50 \mathrm{mmol} / \mathrm{mol} \\
\mathrm{n}=682\end{array}$ & $\begin{array}{c}51-69 \mathrm{mmol} / \mathrm{mol} \\
\mathrm{n}=698\end{array}$ & $\begin{array}{c}\geq 70 \mathrm{mmol} / \mathrm{mol} \\
\mathrm{n}=163\end{array}$ \\
\hline Age at diagnosis & $13.9 \pm 2.5$ & $14.6 \pm 2.3$ & $13.3^{*} \pm 2.5$ & $13.5^{*} \pm 2.5$ \\
\hline Duration of follow up & $7.1 \pm 2.5$ & $6.6 \pm 2.5$ & $7.5^{*} \pm 2.4$ & $7.7^{*} \pm 2.6$ \\
\hline Mean HbA1c in SWE & $60.7 \pm 13$ & $51.7 \pm 10$ & $65.2^{*} \pm 9$ & $78.9^{*} \pm 10$ \\
\hline Mean HbA1c in NDR & $66.7 \pm 16$ & $61.1 \pm 14$ & $69.4^{*} \pm 14$ & $78.8^{*} \pm 17$ \\
\hline Last HbA1c in NDR & $67 \pm 16$ & $62 \pm 16$ & $69.3^{*} \pm 15$ & $78^{*} \pm 18$ \\
\hline Last BMI (kg/m2) & $24.5 \pm 4.2$ & $24.1 \pm 4.1$ & $24.7 \pm 4$ & $25.2 \pm 4.9$ \\
\hline $\begin{array}{c}\text { Last Blood pressure, syst, } \\
\text { mm/Hg }\end{array}$ & $118 \pm 11$ & $117 \pm 11$ & $119 \pm 11$ & $118 \pm 13$ \\
\hline $\begin{array}{c}\text { Last Bloodpressure, diast } \\
\text { mm/Hg }\end{array}$ & $70 \pm 9$ & $70 \pm 8$ & $71 \pm 8$ & $72 \pm 10$ \\
\hline Last Cholesterol mmol/1 & $4.5 \pm 0.9$ & $4.4 \pm 0.9$ & $4.5 \pm 0.9$ & $4.6 \pm 1.0$ \\
\hline Male/Females & $920 / 623(60 / 40)$ & $416 / 266(61 / 39)$ & $414 / 284(59 / 41)$ & $90 / 73(55 / 45)$ \\
\hline Last physical activity, mean & $3.5 \pm 1,2$ & $3.5 \pm 1.1$ & $3.5 \pm 1.2$ & $3.1^{*} \pm 1.3$ \\
\hline Smokers (\%) & 18.2 & 14.5 & $18.4^{\#}$ & $36.0^{*}$ \\
\hline Microalbuminuria (\%) & 5.8 & 5.7 & 4.9 & $8,2^{\#}$ \\
\hline Macroalbuminuria (\%) & 1.1 & 0.5 & 0.6 & $5.6^{*}$ \\
\hline Retinopathy (\%) & 21.1 & 16.2 & $23.1^{\alpha}$ & $31.2^{*}$ \\
\hline
\end{tabular}

Table 2.Clinical characteristics and first time microalbuminuria, marcroalbuminuria and retinopathy in the three HbA1c subgroups. The group with $\mathrm{HbA} 1 \mathrm{c} \leq 50 \mathrm{mmol} / \mathrm{mol}(6.7 \%)$ months $3-15$ after diagnosis is the reference, mean values $=\mathrm{t}$-test, proportion $(\%)=$ chi square. $* \mathrm{p}<0.001, \mathrm{a}<0.01, \#<0.05$ 


\begin{tabular}{|c|c|c|c|c|}
\hline & R-square & Beta-coefficient $(95 \%$ CI $)$ & $\mathrm{t}$ & $\mathrm{p}$ \\
\hline Unadjusted & 0.159 & $0.466(0.408-0.525)$ & 15.6 & 0.001 \\
\hline Adjusted & 0.206 & $0.414(0.355-0.473)$ & 13.2 & 0.001 \\
\hline
\end{tabular}

Table 3. Multivariate linear regression with mean-HbA1c in NDR as dependent and mean HbA1c months $3-15$ after diagnosis as independent. The beta-coefficient relates to the mean-HbA1c value months 3 - 15 after diagnosis. Adjusted value includes age at diagnosis, gender, duration of diabetes, smoking and physical activity in NDR 


\begin{tabular}{|c|c|c|c|c|c|c|}
\hline & \multicolumn{3}{|c|}{ Unadjusted OR with 95\% CI } & \multicolumn{3}{c|}{ Adjusted OR with 95\% CI } \\
\hline & $\begin{array}{c}\text { Macro } \\
\text { albuminuria }\end{array}$ & $\begin{array}{c}\text { Micro } \\
\text { albuminuria }\end{array}$ & Retinopathy & $\begin{array}{c}\text { Macro } \\
\text { albuminuria }\end{array}$ & $\begin{array}{c}\text { Micro } \\
\text { albuminur } \\
\text { ia }\end{array}$ & Retinopathy \\
\hline$\leq 50 \mathrm{mmol} / \mathrm{mol}$ & 1 & 1 & 1 & 1 & 1 & 1 \\
\hline $51-69 \mathrm{mmol} / \mathrm{mol}$ & 1.3 & 0.9 & $1.6^{*}$ & 0.6 & 0.9 & $1.4 \#$ \\
& $(0.3-6.0)$ & $(0.5-1.4)$ & $(1.2-2.1)$ & $(0.1-6.9)$ & $(0.6-1.7)$ & $(1.1-1.9)$ \\
\hline$\geq 70 \mathrm{mmol} / \mathrm{mol}$ & $12.3^{*}$ & $2.0^{\#}$ & $2.6^{*}$ & $14.3^{*}$ & 1.7 & $2.0^{*}$ \\
& $(3.2-46.8)$ & $(1.1-3.8)$ & $(1.7-3.8)$ & $(2.6-78.2)$ & $(0.8-3.4)$ & $(1.2-3.1)$ \\
\hline
\end{tabular}

Table 4. Logistic regression model with OR. Included variables in adjusted OR were gender, duration of type 1 diabetes, age at diagnosis, physical activity registered in NDR and smoking registered in NDR. $*<0.01$, \#<0.05. 


\section{Legends}

Figure 1. The relationship between mean HbA1c (mmol/mol) months 3 - 15 after diagnosis diagnosis in childhood and mean HbA1c in the NDR. 


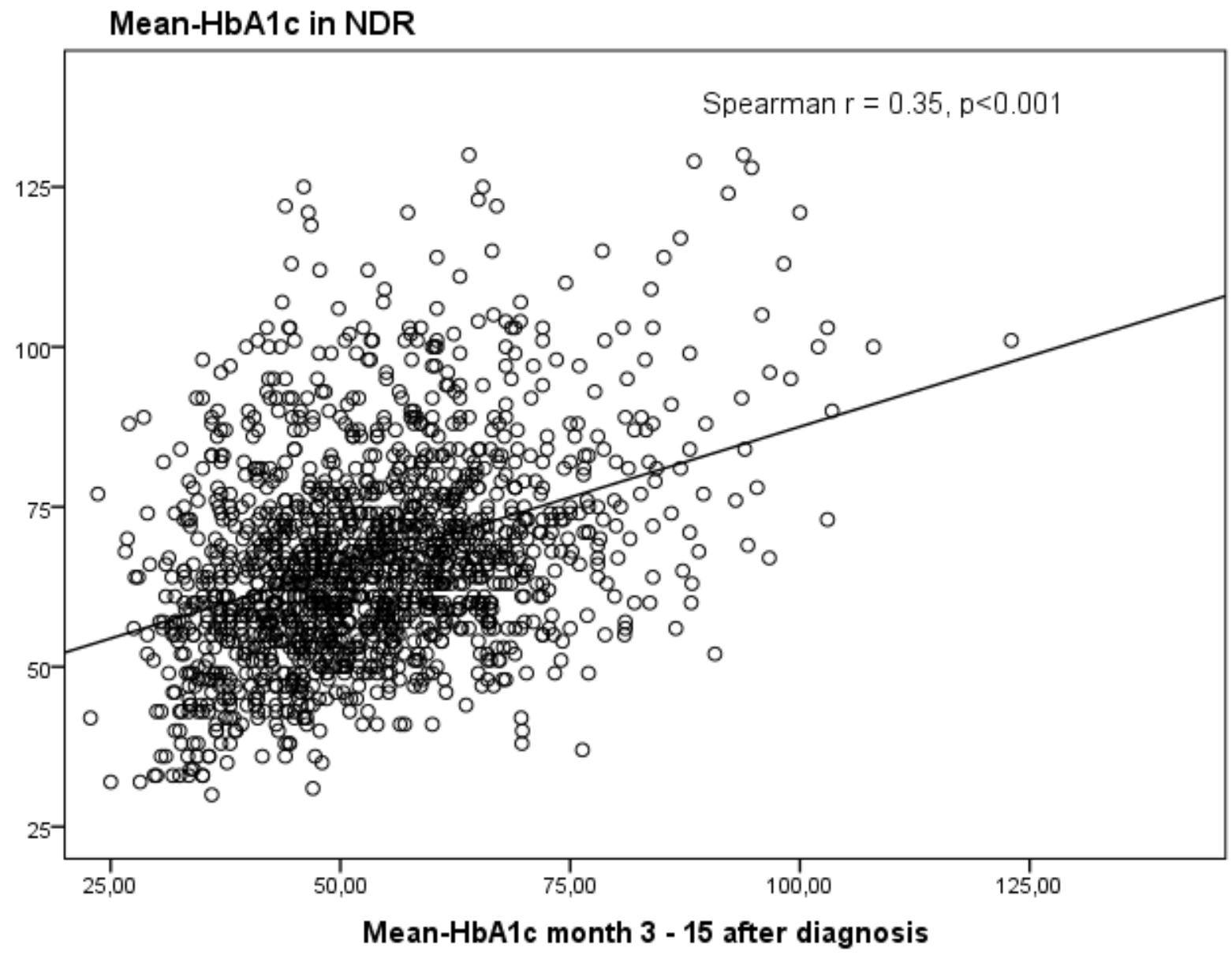

Figure 1. 


\section{References}

1. The effect of intensive treatment of diabetes on the development and progression of long term complications in insulin dependent diabetes mellitus. N Engl J Med. 1993;329:977-86.

2. Olsen, BS, Sjølieb AK, Hougaard P, Johannesen J, Marinelli K, Jacobsen BB, Mortensen HB, Danish Study Group of Diabetes in Childhood: The significance of prepubertal duration of the development of retinopathy and nephropathy in patients with type 1 diabetes. J Diabetes Complications 2004; 18: 160 - 164.

3. Nordwall M, Arnqvist HJ, Bojestig M, Ludvigsson J: Good glycemic control remains crucial in prevention of late diabetes complications - the Linkoping Diabetes Complications Study. Pediatr Diabetes 2009; 10:168-76.

4. Nordwall M, Hyllienmark L, Ludvigsson J: Early diabetic complications in a population of young patients with type 1 diabetes mellitus despite intensive treatment. J Pediatr Endocrinol Metab 2006; 19:45-54.

5. Shalitin S, Phillip M: Which factors predict glycemic control in children diagnosed with type 1 diabetes before 6.5 years of age? Acta Diabetol 2012; 49:355 - 362.

6. Viswanathan V, Sneeringer MR, Miller A, Eugster EA, DiMeglio LA: The utility of hemoglobin A1c at diagnosis for prediction of future glycemic control in children with type 1 diabetes. Diabetes Res Clin Pract 2011; 92:65-68.

7. Nardi L, Zucchini S, D’Álberton FD, Salardi S, Maltoni G, Bisacchi N, Elleri D, Cicognani A: Quality of life, psychological adjustment and metabolic control in youths with type 1 diabetes: a study with self- and parent-report questionnaires. Pediatr Diabetes 2008; 9:496-503.

8. Wysocki T, Lochrie A, Antal H, Buckloh LM: Youth and parent knowledge and communication about major complications of type 1 diabetes: associations with diabetes outcomes. Diabetes Care 2011; 34:1701-5.

9. Hanberger L, Samuelsson U, Berterö C, Ludvigsson J: The influence of structure, process, and policy on $\mathrm{HbA}(1 \mathrm{c})$ levels in treatment of children and adolescents with type 1 diabetes. Diabetes Res Clin Pract 2012; 96: 331-338.

10. Hanas R, John G. 2010 consensus statement on the worldwide standardization of the haemoglobin A1c measurement. Diabetes Care 2010; 33: 1903-1904.

11. Nathan, D.M., H. Turgeon, and S. Regan: Relationship between glycated haemoglobin levels and mean glucose levels over time. Diabetologia 2007; 50: 2239-44..

12. Svensson, M., Eriksson JW, and Dahlquist G: Early glycemic control, age at onset, and development of microvascular complications in childhood-onset type 1 diabetes: a population-based study in northern Sweden. Diabetes Care 2004; 27: 955-62.

13. Hochhauser CJ, Rapaport R, Shemesh E, Schmeidler J, Chemtob CM. Age at diagnosis, gender and metabolic control in children with type 1 diabetes. Pediatr Diabetes 2008; 9: 303-307.

14. Setoodeh A, Mostafavi F, Hedayat T: Glycemic control in Iranian Children with Type 1 diabetes Mellitus: Effect of gender. Indian J Pediatr 2012; 79: 896-900. 
15. Hanberger L, Samuelsson U, Lindblad B, Ludvigsson J: A1C in children and adolescents with diabetes in relation to certain clinical parameters: the Swedish Childhood Diabetes Registry. SWEDIABKIDS. Diabetes Care 2008; 31: 927-929.

16. Springer D, Dziura J, Tamborlane Wv, Steffen AT, Ahern JH, Vincent M, Weinzimer SA: Optimal control of type 1 diabetes mellitus in youth receiving intensive treatment. J pediatr 2006; 149: 227-232.

17. Dahlquist G, Blom L, Holmgren G, Hägglöf B, Larsson Y, Wall S: The epidemiology of diabetes in Swedish children 0 - 14 years - a six years prospective study. Diabetologia 1990; 39: 858 - 864 .

18. Fredheim S, Johannesen J, Johansen A, Lyngsøe L, Rida H, Andersen ML, Lauridsen MH, Hertz B, Birkebæk NH, Olsen B, Mortensen HB, Svenson J: Danish Society for Diabetes in Childhood and Adolescence. Diabetic ketoacidosis at onset of type 1 diabetes is associated with future HbA1c levels. Diabetologia 2013; 56: 995-1003.

19. Genuth S: Insights from the diabetes control and complications trial/epidemiology of diabetes interventions and complications study on the use of intensive glycemic treatment to reduce the risk of complications of type 1 diabetes. Endocr Pract 12 (suppl 1) 2006: 34-41.

20. Gallegos-Macias AR, Macias SR, Kaufman E, Skipper B, Kalishman N: Relationship between glycemic control, ethnicity and socioeconomic status in Hispanic and white non-Hispanic youths with type 1 diabetes mellitus. Pediatric diabetes 2003; 4: 19-23.

21. Haugstvedt A, Wentzel-Larsen T, Rokne B, Graue M: Psychosocial family factors and glycemic control among children aged $1-15$ years with type 1 diabetes: a population based survey. BMC Pediatrics 2011; 11: 118.

22. Mortensen HB and Hougaard P: Comparison of metabolic control in a cross-sectional study of 2,873 children and adolescents with IDDM from 18 countries. The Hvidore study Group on Childhood diabetes. Diabetes Care 1997; 20: 714-720.

23. Rosilio M, Cotton JB, Wieliczko MC, Gendrault B, Carel JC, Couvaras O, Ser N, Gillet P, Soskin S, Garandeau P, Stuckens C, Le Luyer B, Jos J, Bony-Trifunovic H, Bertrand AM, Leturcq F, Lafuma A, French Pediatric Diabetes Group: Factors associated with glycemic control. A cross-sectional nationwide study in 2, 579 French children with type 1 diabetes. The French Pediatric Diabetes Group. Diabetes Care 1998; 21: 1146-1153. 